\title{
Sacral osteoid osteoma: A rare cause of back pain in childhood
}

\author{
L Hassini $^{1}$, MA Khalifa ${ }^{1}$, Z Alaya $^{2 *}$, A Siala ${ }^{1}$, W Osman ${ }^{1}$ and K Bouattour ${ }^{1}$ \\ ${ }^{1}$ Department of Orthopeadics, Sahloul Hospital, Faculty of Medicine of Sousse, Tunisia \\ ${ }^{2}$ Department of Internal Medicine, Mohamed Taher Maamouri Hospital, 8000 Nabeul, Tunisia
}

\begin{abstract}
Involvement of the sacrum is extremely rare, and it has also been reported that the diagnosis of osteoid osteoma in the sacrum can be delayed compared to other skeletal locations. We report the case of a six-year-old girl student who complained of chronic back pain for several months and with some relief with non-steroid anti-inflammatory drugs (NSAID). Further investigations, which included bone and CT scan, revealed the presence of an osteoid osteoma at the second sacral vertebra (S2 vertebra). The patient made an excellent recovery after surgical excision.
\end{abstract}

\section{Introduction}

The spine is a rare localization of osteoid osteoma and the sacrum is even more exceptional. Only $2 \%$ of spinal osteoid osteomas are found in the sacrum. The majority of osteoid osteomas occur below the age of 20 . We report a rare case of a six-year-old girl student who complained of chronic back pain for several months, and who felt some relief with non-steroid anti-inflammatory drugs (NSAID). Further investigations, which included bone and CT scan, uncovered the presence of an osteoid osteoma at the second sacral vertebra (S2 vertebra). The patient obtained favorable results after surgical excision.

\section{Observation}

A six-year-old girl Student presented to our outpatient clinic with a chronic back pain evolving for several months and alleviated with non-steroid anti-inflammatory drugs (NSAID). On physical examination, there was pain at palpation of the sacrum but no signs of neurological deficits. Biology tests and plain radiographs of the pelvis were normal (Figure 1). A sacral computerized tomography (CT) was performed to confirm the diagnosis, depicting a well- demarcated hyper dense sclerotic nodular lesion of about $10.6 \mathrm{~mm}$ in size, with its hypodense peripheral rim on the left lamina of S2 vertebra (Figures 2 and 3). A $0.3 \mathrm{~cm}$ nidus was also detected at the center of the reactive bone sclerosis on the CT scan. The lesion was compressing the left S2 root. A magnetic resonance imaging study was performed revealing subtle signal intensity changes in the sacral region in T1 and T2 images (Figures 4 and 5). The lesion was enhanced after gadolinium administration (Figure 6). The patient underwent surgery, and the lesion was completely excised (Figure 7). The histopathological exam reported it as osteoid osteoma (Figure 8). At three-year follow-up, the patient was asymptomatic with no signs of recurrence.

\section{Discussion}

Osteoid osteoma is a benign bone-forming neoplasm, first described by Jaffe in 1935 [1]. Approximately $10 \%$ of all benign bone tumors are osteoid osteomas [2,3]. Any portion of the skeleton may be involved, but it is often found (50-60\% of cases) in the long bones of

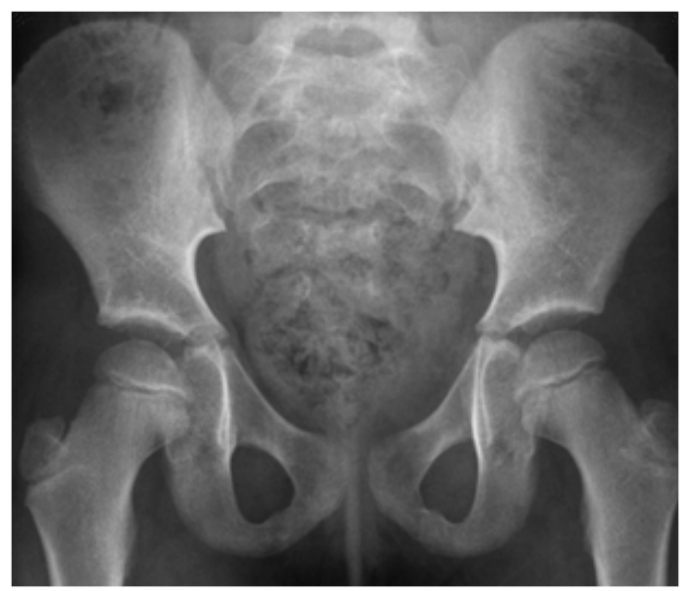

Figure 1. Plain pelvis skiagram including sacral region antero-posterior view. There is no evidence of any lesion or pathology seen in the sacral region

the lower extremity [3] and (between 19 and $31 \%$ of the cases) upper extremity [4,5], whereas about $20 \%$ occur in the spine [6]. $2 \%$ of spinal osteoid osteomas are found in the sacrum [2], and only 19 cases have been reported to date in the English-language literature [7]. Barei et al. have noticed that the majority of osteoid osteomas occur in patients less than 20 years of age [8]. Its pathogenesis is controversial [9]. In fact, it is characterized by a highly innerved and hypervascularized central nidus, surrounded by a reactive peripheric osteogenesis. In the nidus, an important prostaglandin production is observed, causing the pain, and explaining the regression under Acetyl-salicylic acid and other NSAID. Osteoid osteoma clinically manifests with a localized

*Correspondence to: Zeineb Alaya, Department of Internal Medicine, Mohamed Taher Maamouri Hospital, 8000 Nabeul, Tunisia, E-mail: zeineb_a@hotmail.fr

Key words: osteoid, osteoma, sacrum, bone

Received: October 17, 2020; Accepted: November 30, 2020; Published: December 09, 2020 


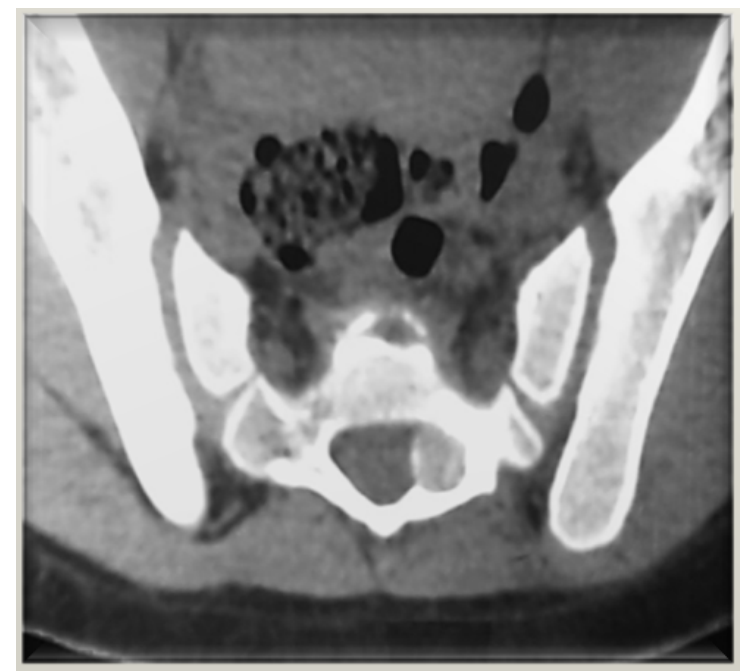

Figures 2. Sacral computerized tomography (CT) shows hypodense lesion with hyperdense central nidus

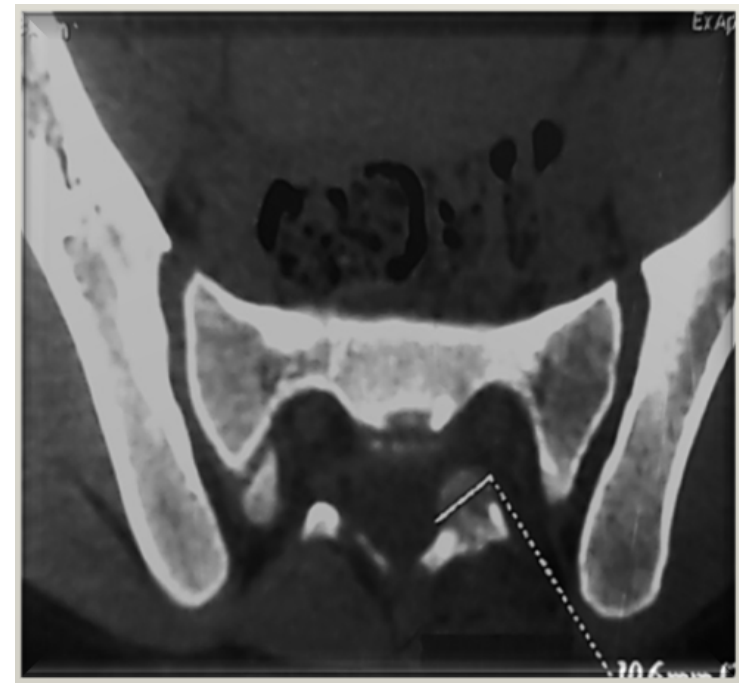

Figures 3. Sacral computerized tomography (CT) shows hypodense lesion with hyperdense central nidus

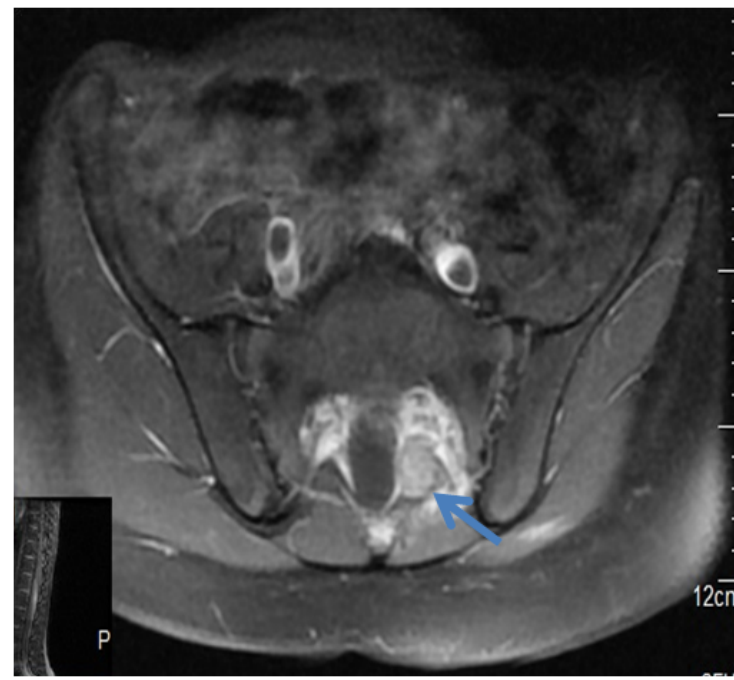

Figures 4. Magnetic resonance imaging study revealed a subtle signal intensity changes in sacral region in T1(a), and T2 images (b), with post gadolinium enhancement of the lesion (c) 


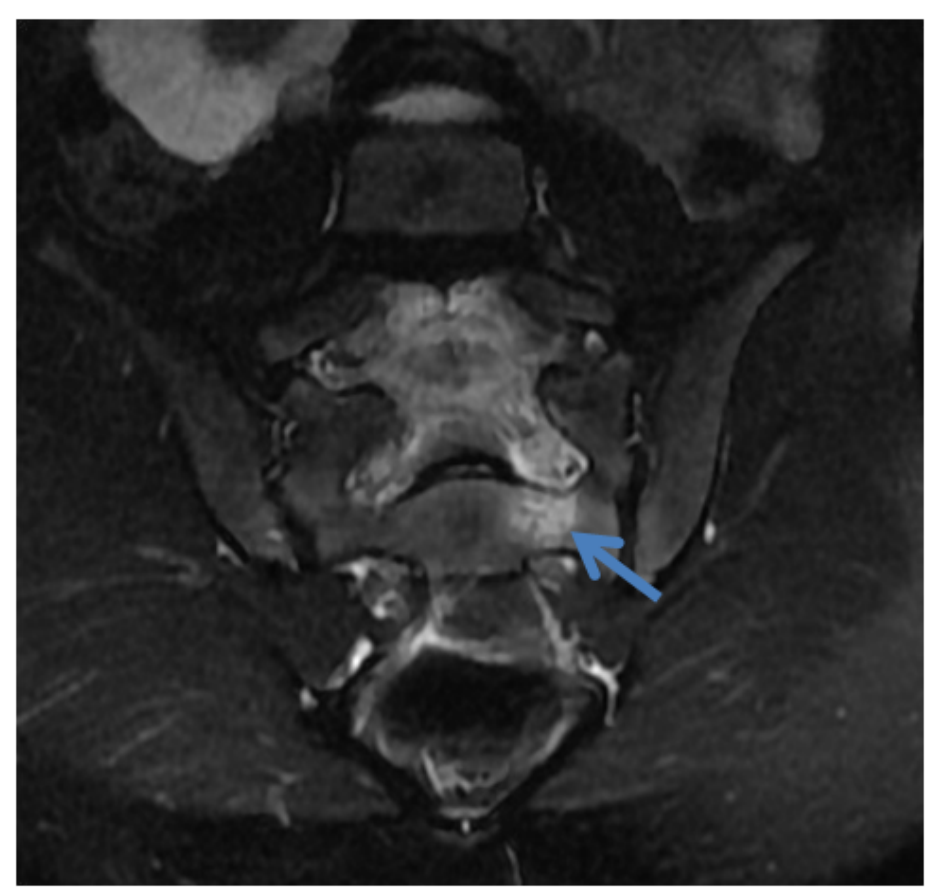

Figures 5. Magnetic resonance imaging study revealed a subtle signal intensity changes in sacral region in T1(a), and T2 images (b), with post gadolinium enhancement of the lesion (c).

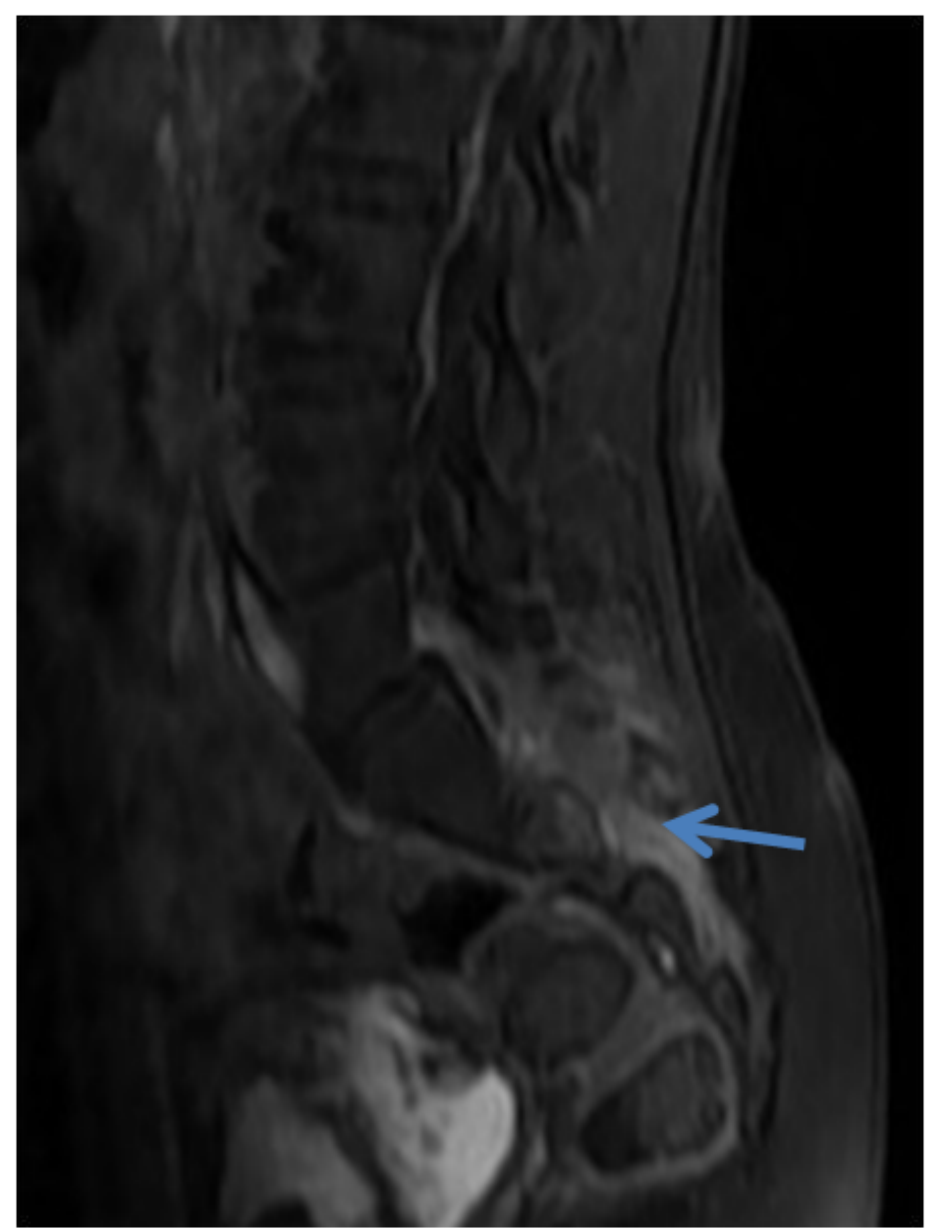

Figures 6. Magnetic resonance imaging study revealed a subtle signal intensity changes in sacral region in T1(a), and T2 images (b), with post gadolinium enhancement of the lesion (c) 


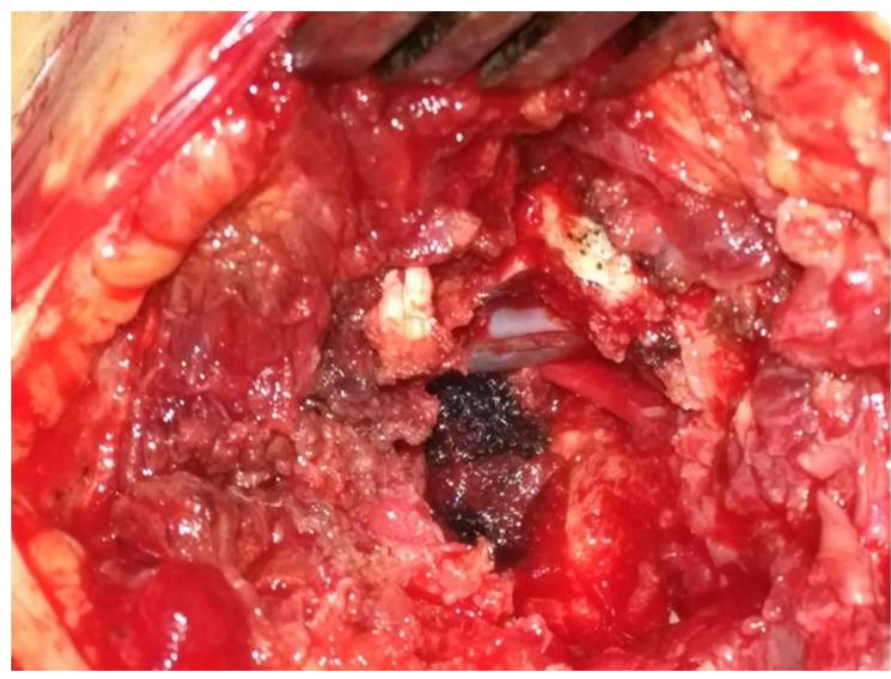

Figure 7. Operative view after tumor excision through a posterior approach

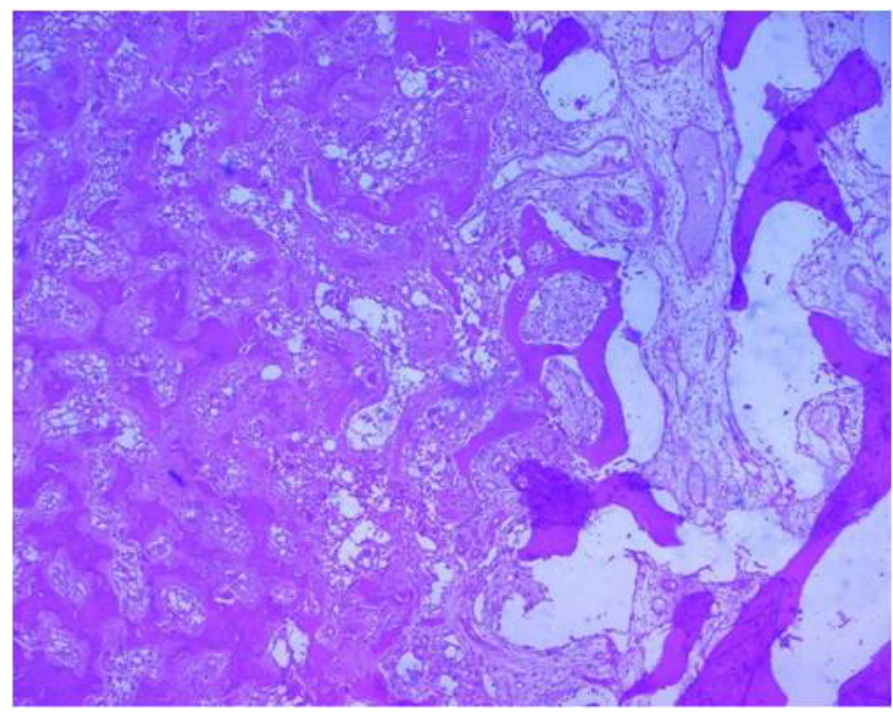

Figure 8. The histological study confirmed the osteoid osteoma

paroxystic nighttime pain. This pain regresses with acetyl-salicylic acid and other NSAID. In our case, the patient complained of chronic back pain of several months' duration and with some relief with nonsteroid anti-inflammatory drugs (NSAID). In the sacrum, when S 1 is involved a marked spinal stiffness is usually present (60\%); in contrast, spinal stiffness is rare when the lesion spares S-1 (20\%). Neurological symptoms are rare (30\%), they are usually found in lesions more than 2 $\mathrm{cm}$ in diameter [10]. Scoliosis is usually present in lesions eccentrically involving either the body or the posterior elements of S-1. When the lesion is located centrally in S-1 or spares it, scoliosis is rare [11]. Plain radiographs rarely allow diagnosis and give poor information about the lesion. The central nidus is rarely seen. However, in case of scoliosis, the lesion could be found in the top of the curve and even on the adjacent ribs. CT is particularly useful for characterizing spinal osteoid osteomas. These lesions typically manifest as low-density nidus in the posterior elements. Many studies have cited the superiority of CT over MRI in both diagnosing and characterizing osteoid osteomas [12]. Technetium-99- labeled bone scintigraphy may prove useful for confirming the diagnosis with a $100 \%$ virtual sensitivity for detection [13]. The management depends on the location, size and the symptoms of the patient. There are various treatment options for this entity and radiofrequency ablation remains the treatment of choice in selected cases with the appropriate setting [14]. The lesion should not be near to the thecal sac and there should be enough cortical bone in the surrounding region. Air in the region can be of benefit being nonconductive of heat. If these conditions are not present, surgical excision becomes the most viable treatment option (reference). Likewise, in our patient the lesion was in close proximity to the left S2 root, which justified a surgical excision.

\section{Conclusion}

Osteoid osteoma is a relatively frequent benign bone tumor of osteoblastic origin. Multicentric, intra- or juxta-articular, medullary and sub-periosteal lesions are called atypical osteoid osteoma. The diagnosis should be referred to as having a low back pain in an infant. CT scan and/or MRI allow to visualize the lesion and its extent to the neural elements. Surgical excision is an effective technique for the obtaining of good clinical results.

\section{Conflict of interest}

The author(s) declare that they have no competing interests.

\section{Authors' contributions}

All authors have read and agreed to the final version of this manuscript and have equally contributed to its content and to the management of the case.

\section{References}

1. Jaffee HL (1935) "Osteoid osteoma," a benign osteoblastic tumor composed of osteoid and atypical bone. Arch Surg 31: 709.

2. Campanacci M (1999) Osteoid osteoma. In: Campanacci M, editor. Bone and soft tissue tumors. $2^{\text {nd }}($ edn). Padova: Piccin Nuova Libraria. Pp: 391-415.

3. Gitelis S, McDonald DJ (1998) Common benign bone tumors and usual treatment In: Simon MA, Springfield DS, editors. Surgery for bone and soft tissue tumors. Philadelphia: Lippincott-Raven. Pp: 181-205.

4. Bednar MS, McCormack Jr RR, Glasser D, Weiland AJ (1995) Osteoid osteoma of the upper extremity. J Hand Surg Am 18: 1019-1025. [Crossref]

5. Arazi M, Memik R, Yel M, Ogun TC (2001) Osteoid osteoma of the carpal bones. Arch Orthop Trauma Surg 121: 119-120. [Crossref]

6. Jackson RP, Reckling FW, Mants FA (1977) Osteoid osteoma and osteoblastoma Similar histologic lesions with different natural histories. Clin Orthop Relat Res 128: 303-313. [Crossref]

7. Fukuda S, Susa M, Watanabe I, Nishimoto K, Horiuchi K, et al. (2014) Computed tomography-guided resection of osteoid osteoma of the sacrum: a case report. $J$ Med Case Rep 8: 206.

8. Muller PY, Carlioz H (1999) Recurrence or persistence of an osteoid osteoma: a case report. Rev Chir Orthop Reparatrice Appar Mot 85: 69-74. [Crossref]

9. Weber KL, Morrey BF (1999) Osteoid osteoma of the elbow: a diagnostic challenge. $J$ Bone Joint Surg Am 81: 1111-1119. [Crossref]

10. Themistocleous GS, Chloros GD, Benetos IS, Efstathopoulos DG, Gerostathopoulos $\mathrm{NE}$, et al. (2006) Osteoid osteoma of the upper extremity: a diagnostic challenge. Chirurgie de la Main 25: 69-76.

11. Lee EH, Shafi M, Hui JH (2006) Osteoid osteoma: a current review. J Pediatr Orthop 26: 695-700.

12. Themistocleous GS, Chloros GD, Benetos IS, Efstathopoulos DG, Gerostathopoulos NE, et al. (2006) Osteoid osteoma of the upper extremity: a diagnostic challenge. Chirurgie de la Main 25: 69-76.

13. Wells RG, Miller JH, Sty JR (1987) Scintigraphic patterns in osteoid osteoma and spondylolysis. Clin Nucl Med 12: 39-44. [Crossref]

14. Zileli M, Cagli S, Basdemir G, Ersahin Y (2003) Osteoid osteomas and osteoblastomas of the spine. Neurosurg Focus 15: E5. [Crossref]

Copyright: (C2020 Hassini L. This is an open-access article distributed under the terms of the Creative Commons Attribution License, which permits unrestricted use, distribution, and reproduction in any medium, provided the original author and source are credited. 